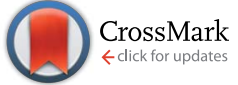

Cite this: RSC Adv., 2017, 7, 3059

\title{
Enhanced charge carrier transport in spray-cast organic solar cells using solution processed $\mathrm{MoO}_{3}$ micro arrays
}

\begin{abstract}
Ran Ji, ${ }^{a}$ Jiang Cheng, ${ }^{a b}$ Xin Yang, ${ }^{a b}$ Junsheng Yu*a and Lu Li*b
A toward all spray fabrication routine was used to fabricate organic solar cells (OSCs), in which a molybdenum oxide $\left(\mathrm{MoO}_{3}\right)$ micro array was directly deposited on the active layer, and the influence of the hole transporting property on the OSC performance was studied. The component and morphology of the $\mathrm{MoO}_{3}$ array as well as the effect on OSCs performance has been investigated. By using the solution processed $\mathrm{MoO}_{3}$, we obtained a $62.7 \%$ enhancement to $3.4 \%$ in PCE compared to the non- $\mathrm{MoO}_{3}$ device base on the P3HT system. Photovoltaic measurement and impedance analysis indicated that the $\mathrm{MoO}_{3}$ micro array has modified the interface between the electron donor and anode. By improving the ratio of the precursor solvent, the carrier transport performance was further improved. This approach significantly enhances our understanding of the application of $\mathrm{MoO}_{3}$ micro arrays in all-sprayed OSCs, and indicating that this simple method has good prospects for the handy commercial fabrication of OSCs.
\end{abstract}

Received 1st December 2016 Accepted 21st December 2016

DOI: $10.1039 / c 6 r a 27647 d$

www.rsc.org/advances efficient OSCs using a spray coated processing technique. In our previous work, a high PCE of $7.62 \%$ for the OSCs with a pneumatic spray coated PTB7:PC ${ }_{71} \mathrm{BM}$ was achieved. ${ }^{17}$ However, the study of spray coated buffer layer is very limited. Polymer buffer layers are more inclined to be chosen for the fabrication of all sprayed OSCs, because they are easily dissolved in organic solvents. However, polymer buffer layers usually have a low stability, resulting in an unsatisfactory lifetime. For example, the widely used ABL PEDOT:PSS is both hygroscopic and acidic, which has an associated reduction in device stability. ${ }^{18}$ Inorganic buffer layers are much more stable and suitable for high lifetime OSCs preparation. Unfortunately, it is much difficult to deposition inorganic buffer materials by solution method especially on active layer, since they usually need a high substrate temperature for annealing, even some of the raw materials could not be solubilized.

Recently, a solution process of $\mathrm{ZnO} \mathrm{CBL}$ was processed at a comfortable low temperature $\left(\sim 150{ }^{\circ} \mathrm{C}\right)$ by an ultrasonic spray pyrolysis using zinc-ammonia solution. And a PCE of $3.7 \%$ for the rigid P3HT:PCBM solar cells and a PCE of $2.8 \%$ for the flexible solar cells were reported. ${ }^{19}$ This low temperature solution process encouraged us to deposit inorganic ABLs on the organic active layer directly to develop a simple all-spray coating routine for preparing OSCs. As well known, the promising alternative ABLs are metal oxide with strong hole-transporting ability and stability such as molybdenum oxide $\left(\mathrm{MoO}_{3}\right){ }^{\mathbf{2 0 - 2 3}}$ vanadium oxide $\left(\mathrm{V}_{2} \mathrm{O}_{5}\right),{ }^{21,23}$ and nickel oxide $(\mathrm{NiO}) .^{24,25}$ In particular, $\mathrm{MoO}_{3}$ is non-toxic and possesses deep-lying electronic states to be one of the most promising materials for the fabrication of high efficiency OSCs. ${ }^{5}$

In this study, our initial aim is to develop an ultrasonic spray coating method for low temperature deposition of $\mathrm{MoO}_{3}$ film.

\footnotetext{
${ }^{a}$ State Key Laboratory of Electronic Thin Films and Integrated Devices, School of Optoelectronic Information, University of Electronic Science and Technology of China, Chengdu 610054, P. R. China

${ }^{b}$ Co-Innovation Center for Micro/Nano Optoelectronic Materials and Devices, Research Institute for New Materials and Technology, Chongqing University of Arts and Sciences, Chongqing 402160, P. R. China
} 
(a)

We chose the easily decomposed material ammonium heptamolybdate $\left(\left(\mathrm{NH}_{4}\right)_{6} \mathrm{Mo}_{7} \mathrm{O}_{24} \cdot 4 \mathrm{H}_{2} \mathrm{O}\right)$ as the precursor solution. However, we found that $\mathrm{MoO}_{3}$ is not apt to form continuous film on all substrates that we have tried including P3HT:PCBM blend film. Microscope shows that P3HT:PCBM was discrete $\mathrm{MoO}_{3}$ micro arrays. Nevertheless, we found that the micro arrays have the similar function of improving the interfacial contact as $\mathrm{MoO}_{3}$ thin film, and a $62.7 \%$ enhancement to $3.4 \%$ in PCE compared to non- $\mathrm{MoO}_{3}$ P3HT:PCBM solar cells was obtained. In particular, most parts of OSCs except the silver anode are fabricated by spray-coating method under atmospheric condition, which was one step closer to the realization of lowcost, high lifetime and large-scale OSCs.

\section{Experimental}

\subsection{Fabrication section}

The configuration of photovoltaic device is ITO/ZnO $(40 \mathrm{~nm}) /$ P3HT: $\mathrm{PC}_{61} \mathrm{BM}(300 \mathrm{~nm}) / \mathrm{MoO}_{3}$ array/Ag $(100 \mathrm{~nm})$, as shown in Fig. 1(a). Patterned ITO-coated glass substrates with a sheet resistance of $10 \Omega \mathrm{sq}^{-1}{ }^{-1}$ were consecutively cleaned in ultrasonic bath containing detergent, acetone, deionized water and ethanol for 10 min each step, then dried by nitrogen blow. A $50 \mathrm{~nm}$ ZnO layer was then grown on ITO film by ultrasonic spray pyrolysis at $150{ }^{\circ} \mathrm{C}$ as we depicted in our published works. ${ }^{19,26}$ Then, a $300 \mathrm{~nm}$ active layer of $\mathrm{P} 3 \mathrm{HT}: \mathrm{PC}_{61} \mathrm{BM}$ was cast from a solution with P3HT (99.9\%, Aldrich) and (6,6)-phenyl-PCBM $(99.9 \%$, Lumtec) at ratio of $1: 0.9 \mathrm{wt} \%$ in 1,2-dichlorobenzene (DCB) at a concentration of $5 \mathrm{mg} \mathrm{ml}^{-1}$. The spray rate of P3HT: $\mathrm{PC}_{61} \mathrm{BM}$ solution was $0.075 \mathrm{ml} \mathrm{min}^{-1}$ and the $\mathrm{N}_{2}$ carrier gas flow rate was held at a rate of $18 \mathrm{~L} \mathrm{~min}^{-1}$. $\mathrm{MoO}_{3}$ was deposited on P3HT:PCBM blend film by ultrasonic spray pyrolysis at $80{ }^{\circ} \mathrm{C}$ using $\mathrm{N}_{2}$ as carrier gas at a flow rate of $10 \mathrm{~L}$ $\min ^{-1}$, solution atomization rate was approximately $3 \mathrm{ml}$ $\min ^{-1}$. The spray apparatus was consisted of an ultrasonic transducer, an atomization chamber, an automatic $X-Y$ table, a heating block and pipe fittings, as shown in Fig. 1(b). The ultrasonic transducer continuously converts solution into mist, which could be transport by carrier gas and then deposited on the surface of substrate. $\mathrm{MoO}_{3}$ precursor were carried out by dissolving ammonium heptamolybdate $\left(\left(\mathrm{NH}_{4}\right)_{6} \mathrm{Mo}_{7} \mathrm{O}_{24} \cdot 4 \mathrm{H}_{2} \mathrm{O}\right)$ in deionized water mixed with one or several organic solvents (methanol, isopropanol) with a desired concentration (0.2 wt\%).

\subsection{Measurement method}

The composition and electron structure of the $\mathrm{MoO}_{3}$ micro array was characterized by using X-ray photoelectron spectroscopy (XPS, Thermo ESCALAB). Surface morphology of the $\mathrm{MoO}_{3}$ micro array was characterized by three-dimensional microscope (DSX500, Olympus) and scanning electronic microscope (SEM, S4800 Hitachi). Current density-voltage $(J-V)$ curves were measured using Keithley 2400 under a xenon lamp solar simulator (7IS0503A, Beijing SOFN) with an illumination power of $100 \mathrm{~mW} \mathrm{~cm}{ }^{-2}{ }^{4}$ All the measurements were carried out at ambient circumstance without encapsulation.

\section{Results and discussion}

\section{$3.1 \mathrm{MoO}_{3}$ spraying process}

To accomplish a good uniformity for the films, the sprinkler is passed over the hot plate which was driven by the drive $X-Y$ table. The sprinkler performed an S-shaped curve relative motive with the substrate. The precursor was atomized, transported and the decomposed to $\mathrm{MoO}_{3}, \mathrm{NH}_{3}$ and $\mathrm{H}_{2} \mathrm{O}$, among which $\mathrm{NH}_{3}$ is gaseous, and $\mathrm{MoO}_{3}$ is expected to be the only solute in the solution..$^{27,28}$ After the deposition process, the wafers were sequentially annealed in situ for $2 \mathrm{~min}$ to form a stable structure for $\mathrm{MoO}_{3}$.

\subsection{Component analysis by XPS}

The surface characteristics of the $\mathrm{MoO}_{3}$ on silicon wafer were characterized by XPS. Before testing, $\mathrm{MoO}_{3}$ were etched using argon plasma for approximately $10 \mathrm{~nm}$. The full scan spectrums of solution processed $\mathrm{MoO}_{3}$ with thermal evaporated $\mathrm{MoO}_{3}$ were shown in Fig. 2(a and b). $\mathrm{O}$ 1s and Mo 3d peaks of the two samples are shown in Fig. 2(c, d) and (e, f), respectively. The two full scan spectra are difficult to distinguish. Two main XPS resolved peaks 

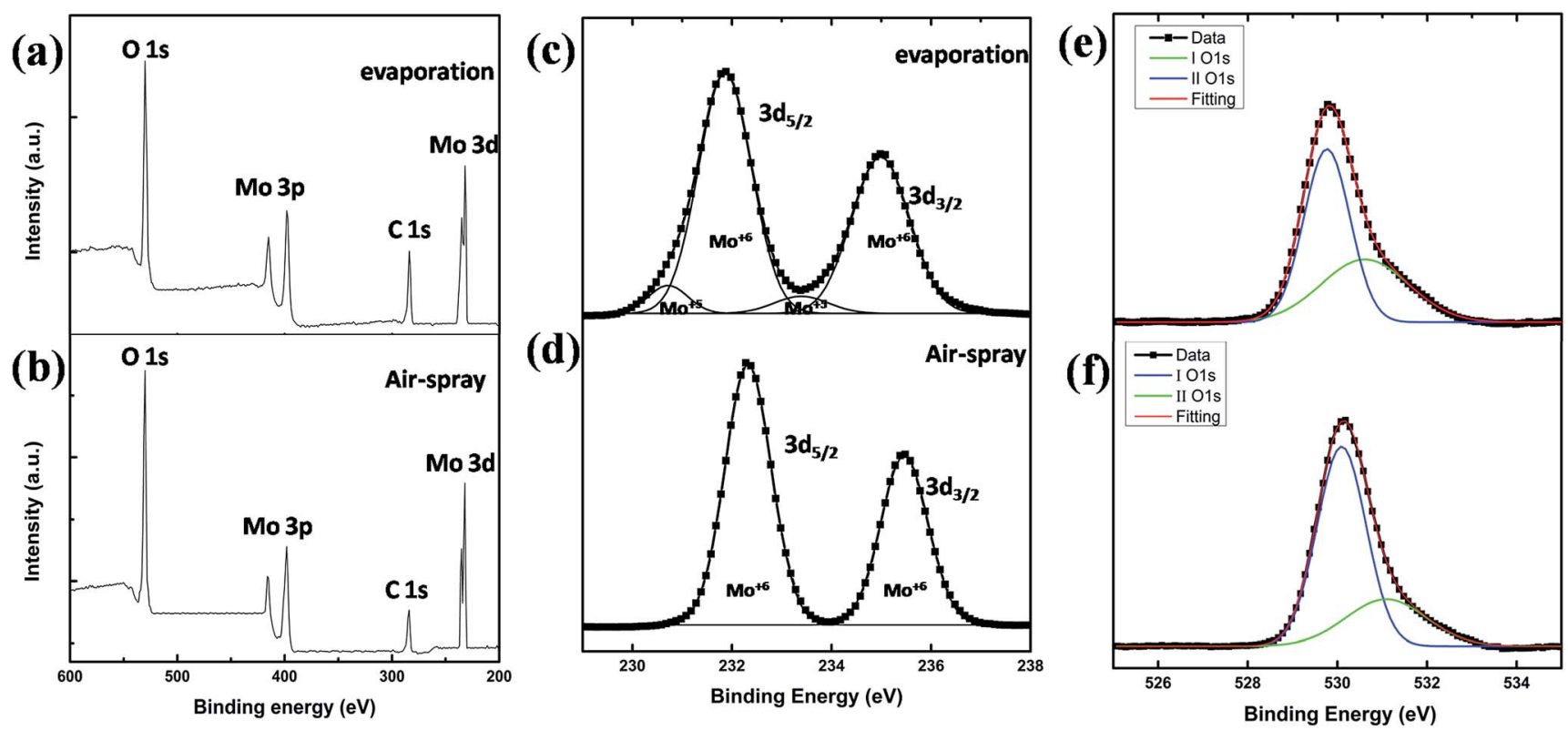

Fig. 2 XPS spectra of different process $\mathrm{MoO}_{3}$ films. (a), (c) and (e) Full scan, Mo $3 \mathrm{~d}$ core levels, $\mathrm{O}$ 1s core levels, deposited by vacuum thermal evaporation, respectively. (b), (d) and (f) Full scan, Mo 3d core levels, O 1s core levels, spray-coated in air, respectively.

belong to the typical doublet of $\mathrm{Mo}^{6+}$ at $232.2 \mathrm{eV}$ and $235.5 \mathrm{eV}$ are easy to be observed. ${ }^{5}$ By a more detailed analysis, the O $1 \mathrm{~s}$ XPS spectrum exhibits asymmetric line shapes (Fig. 2(e and f)). The peak with lower binding (529.8 to 530.1) energy corresponds to $\mathrm{O}$ atoms in $\mathrm{MoO}_{3}$ matrix. The second peak, at 530.5 to $531.0 \mathrm{eV}$ is probably due to oxide impurities accumulated. ${ }^{29}$ The relative magnitude of the high-binding-energy $\mathrm{O}$ atoms was $35 \%$ in thermal enveloped $\mathrm{MoO}_{3}$ and $24 \%$ in solution processed $\mathrm{MoO}_{3}$, indicating the solution processed $\mathrm{MoO}_{3}$ has a more perfect composition than thermal evaporated. $\mathrm{Mo}^{5+}$ doublet at 233.4 and 230.7 of thermal evaporated $\mathrm{MoO}_{3}$ can also be detected by peak fitting analysis. The relative magnitude of $\mathrm{Mo}^{5+} / \mathrm{Mo}^{6+}$ is approximately $10 \%$. On the contrary, the high resolution XPS spectrum of solution processed $\mathrm{MoO}_{3}$ reveals only $\mathrm{Mo}^{6+}$ oxidation state. It means that solution processed $\mathrm{MoO}_{3}$ films have less oxygen vacancies. The saturated valence state of Mo indicated that it is stable. The solution processed $\mathrm{MoO}_{3}$ might have a better performance in hole transporting than thermal evaporated sample, due to the less oxide impurities and stable Mo valence state. Thus, as an ABL material, the solution processed $\mathrm{MoO}_{3}$ is less sensitive to thickness than the evaporated $\mathrm{MoO}_{3}$.

\subsection{Deionized water as precursor solution}

Initially, a very interesting phenomenon in our prepared $\mathrm{MoO}_{3}$ on P3HT:PCBM blend films was observed when the deionized water was the only solvent of precursor. $\mathrm{MoO}_{3}$ tended to form micro arrays instead of uniform films on the surface of active layer as well as the other substrates we have tried. As we seen in Fig. 3, the microscope image shows the spray-casted $\mathrm{MoO}_{3}$ micro array was consisted of a series of island of varying sizes. The size of islands shifted to larger when the spray time increased. Surprisingly, the density of micro islands is almost constant at approximately $1.8 \times 10^{3}$ $\mathrm{mm}^{-2}$. In conclusion, the $\mathrm{MoO}_{3}$ deposited by water solution of $\left(\mathrm{NH}_{4}\right)_{6} \mathrm{Mo}_{7} \mathrm{O}_{24} \cdot 4 \mathrm{H}_{2} \mathrm{O}$ is apt to gather into islands and aligning to grid.

\subsection{Multicomponent solvent system (MSS)}

As the deionized water has a low vapor pressure and cannot volatilize from droplet timely, we conducted a systematic study of a multicomponent solvent system consisted of deionized water (DW), methanol (ME) and isopropanol

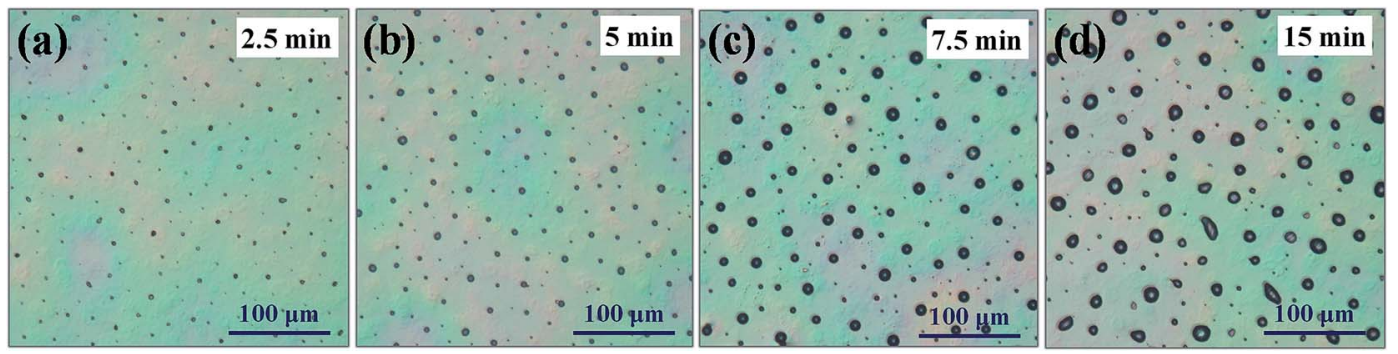

Fig. 3 Microscope images of $\mathrm{MoO}_{3}$ array with water solvent in different spray time. (a) $2.5 \mathrm{~min}$ (b) 5 min (c) 7.5 min (d) 15 min (one cycle of $X-Y$ table running time is $2.5 \mathrm{~min}$ ). 
Table 1 Comparison of device characteristics of OSCs based on $\mathrm{MoO}_{3}$ micro array with different MSSs

\begin{tabular}{|c|c|c|c|c|}
\hline & $V_{\mathrm{OC}}(\mathrm{mV})$ & $J_{\mathrm{SC}}\left(\mathrm{mA} \mathrm{cm}^{-2}\right)$ & $\mathrm{FF}(\%)$ & PCE $(\%)$ \\
\hline Thermal evaporated $5 \mathrm{~nm} \mathrm{MoO}_{3}$ & 590 & 9.07 & 60.2 & 3.23 \\
\hline Thermal evaporated $30 \mathrm{~nm} \mathrm{MoO}_{3}$ & 577 & 7.52 & 54.3 & 2.36 \\
\hline DW & 603 & 8.35 & 56.0 & 2.82 \\
\hline
\end{tabular}

Solvent (vol\%)

$I P A: D W$

$20: 80$

$40: 60 \quad 598$

$60: 40$

$80: 20$

$M E: D W$

$20: 80$

$40: 60$

$60: 40$

$80: 20$

$I P A: M E: D W$

$10: 30: 60$

$20: 20: 60$

598
593

600

9.03

9.36

8.07

6.77

$\begin{array}{ll}596 & 8.82 \\ 596 & 8.33\end{array}$

$\begin{array}{ll}597 & 7.95\end{array}$

$604-7.03$

7.03

$599 \quad 9.42$

9.51

9.61

$\begin{array}{ll}56.2 & 3.03 \\ 58.8 & 3.25 \\ 45.6 & 2.19 \\ 31.0 & 1.26 \\ & \\ 57.8 & 3.03 \\ 56.2 & 2.79 \\ 44.0 & 2.09 \\ 25.5 & 1.08 \\ & \\ 55.9 & 3.16 \\ 59.1 & 3.37 \\ 59.2 & 3.40\end{array}$
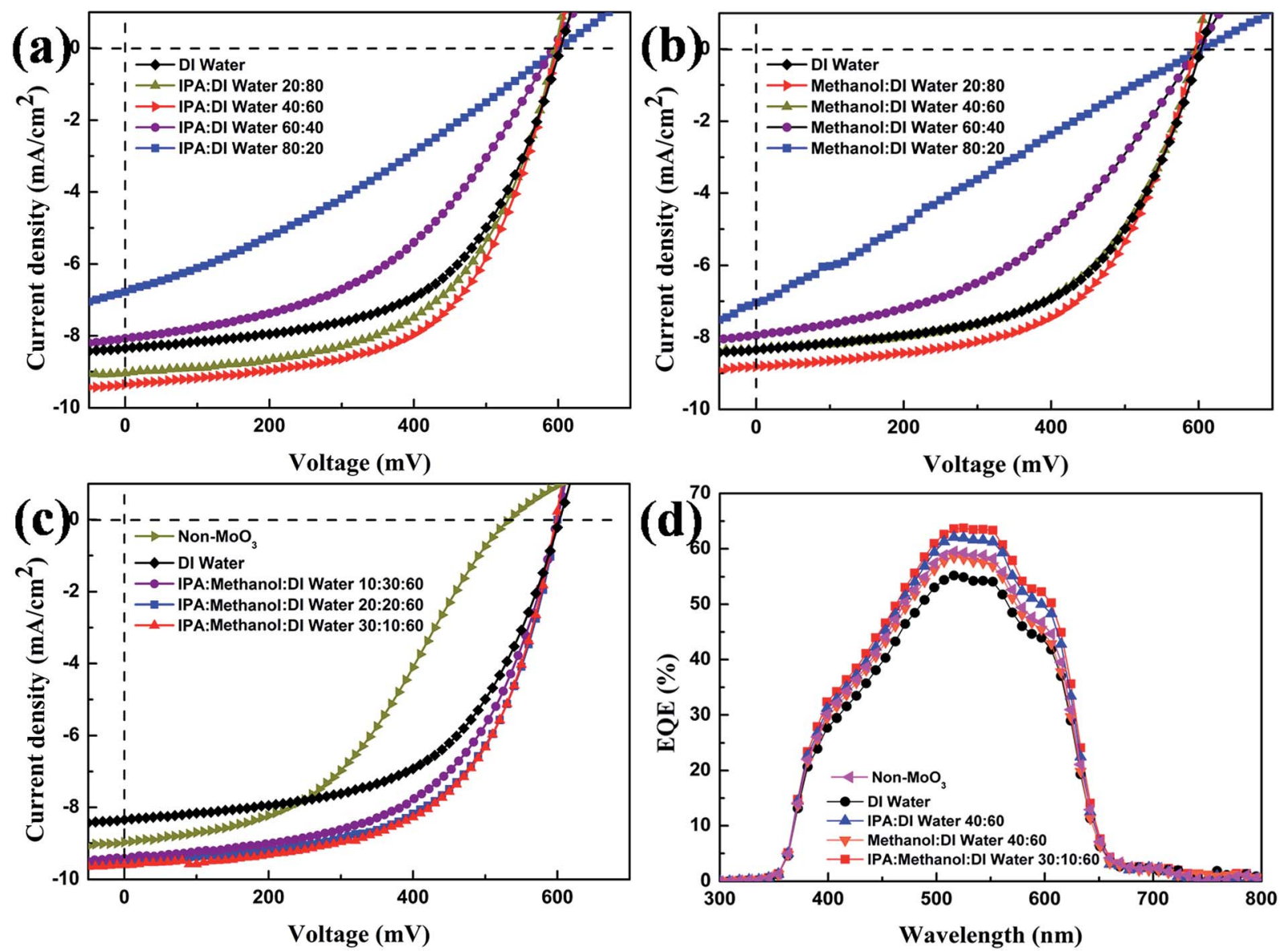

Fig. 4 (a), (b) and (c) J-V characteristics of OSCs with different MSSs; (d) EQE characteristics of OSCs based on MoO 3 micro array in different MSSs. 


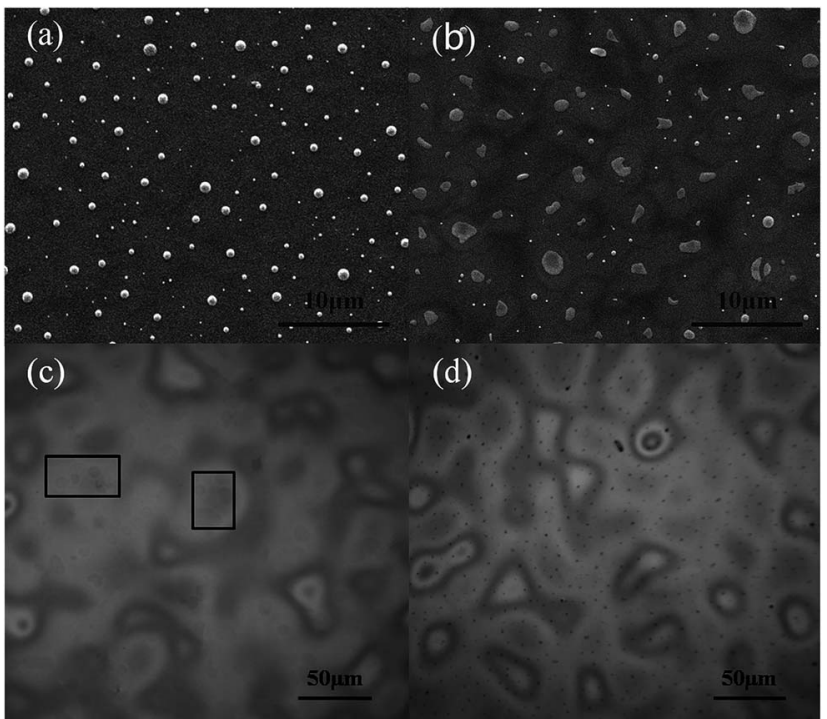

Fig. 5 SEM images of $\mathrm{MOO}_{3}$ micro array with different MSS of (a) DW; (b) DW : IPA : ME (60:30:10 vol\%). Metallographic microscope images of active layer with different MSS of (c) IPA : DW (80: 20 vol\%); (d) ME : DW (80: 20 vol\%).

(IPA) as the solvent of $\mathrm{MoO}_{3}$ precursor solution. The effect of MSS on the performance of spray coated OSCs was investigated. We prepared 4 samples in parallel, each sample having 4 cells with an active area of $0.07 \mathrm{~cm}^{2}$. The device performances are summarized in Table 1 and Fig. 4.

For the device without $\mathrm{MoO}_{3} \mathrm{ABL}$, the PCE was only $2.09 \%$ with an open circuit voltage $\left(V_{\mathrm{OC}}\right)$ of $530 \mathrm{mV}$, a short circuit current density $\left(U_{\mathrm{sC}}\right)$ of $8.97 \mathrm{~mA} \mathrm{~cm}{ }^{-2}$, and a fill factor (FF) of $43.8 \%$. The low performance was caused by the poor contact between active layer and Ag. ${ }^{30}$ When the solution processed $\mathrm{MoO}_{3}$ ABLs was employed, the devices showed a consistent improvement on $V_{\mathrm{OC}}$ and $\mathrm{FF}$, resulting in a higher PCE. When using DW at the solvent of precursor, the OSCs yielded an improved PCE of $2.82 \%$. For the IPA : DW MSS, the device showed a gradually rise in performance when IPA ratio increase from 0 to 40 vol\%. Especially, the optimized IPA : DW MSS with a ratio of $40: 60 \mathrm{vol} \%$ presents $12 \%$ enhanced $J_{\mathrm{SC}}$ from 8.35 to $9.36 \mathrm{~mA} \mathrm{~cm}^{-2}$, and $15 \%$ enhanced PCE from $2.82 \%$ to $3.25 \%$. When the IPA volume content ratio exceeds 40 to $80 \mathrm{vol} \%, J_{\mathrm{SC}}$ and PCE gradually decreased to $6.77 \mathrm{~mA} \mathrm{~cm}^{-2}$ and $1.26 \%$. For the ME : DW MSS, similar to the case of IPA : DW MSS, the highest device performance was obtained where the PCE was $3.03 \%$ with $V_{\mathrm{OC}}$ of $596 \mathrm{mV}, J_{\mathrm{SC}}$ of $8.82 \mathrm{~mA} \mathrm{~cm}{ }^{-2}$, and $\mathrm{FF}$ of $57.8 \%$. Compared with the solution processed $\mathrm{MoO}_{3}$, the device with $5 \mathrm{~nm}$ thermal evaporated $\mathrm{MoO}_{3}$ shows a lower $V_{\mathrm{OC}}$ of $590 \mathrm{mV}, J_{\mathrm{SC}}$ of $9.07 \mathrm{~mA} \mathrm{~cm}^{-2}$ and the highest FF of $60.2 \%$. The device with $30 \mathrm{~nm}$ thermal evaporated $\mathrm{MoO}_{3}$ shows a lowest PCE of $2.36 \%$ with $V_{\mathrm{OC}}$ of $577 \mathrm{mV}, J_{\mathrm{SC}}$ of $7.52 \mathrm{~mA} \mathrm{~cm}^{-2}$, and FF of $54.3 \%$. The device performance with thermal evaporated $\mathrm{MoO}_{3}$ is sensitive to the thickness of the ABL.

The performance of OSCs increased with the enhancement of ME or IPA volume in the binary solvent system. However, both of

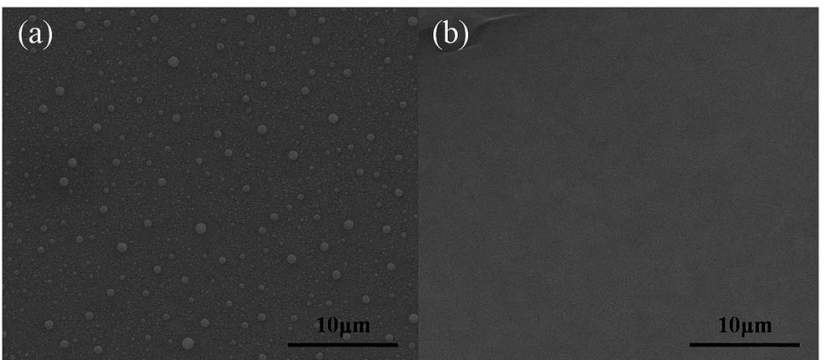

Fig. 6 SEM images of thermal evaporated $\mathrm{MoO}_{3}$ with different thickness of (a) $5 \mathrm{~nm}$; (b) $30 \mathrm{~nm}$.

them exhibit a gradual degradation instead of steady improvement in device performance when the content reached more than $40 \%$. It seems that the water vapor is not the essential effect on the active layer. The surface morphology of $\mathrm{MoO}_{3}$ reveals the nature of the MSS effect on the device, as shown in Fig. 5. When using DW in the solvent of precursor, $\mathrm{MoO}_{3}$ has a less effective contact area with the active layer and the island was nearly spherical. However, when the precursor contained a part of IPA or $\mathrm{ME}$, the $\mathrm{MoO}_{3}$ arrays were composed of flat islands as shown in Fig. 5(b). The roughness of interface decreases obviously. And from the performance respects, the result suggests that the flat $\mathrm{MoO}_{3}$ array can enhance the hole collection at the interface between the ITO and active layer. ${ }^{31}$ Due to the $J_{\mathrm{SC}}$ and FF increased obviously, which resulted in a high PCE. Combining with the broader area of $\mathrm{MoO}_{3}$ islands, we speculate that the charge-carrier transport channel between the active layer and the anode became much broader. The accurate conclusion will be verified in the subsequent experiments.

It is well known that both of IPA and ME are frequently used polar organic solvent, which have been investigated to treat active layer. ${ }^{32,33}$ It is also a reason of performance improved by introducing IPA and ME. However, the increasing content of IPA or ME caused a destruction of the P3HT:PCBM under the condition of annealing. When the concentration reached to a certain amount, it destroyed the morphology of active layer and caused many voids or pinholes as shown in Fig. 5(c and d), leading to a low device performance.

To further improve the performance of OSCs while increasing the repeatability with solution processed $\mathrm{MoO}_{3}$ arrays, a ternary solvent system was introduced. Keeping a proper atomization efficiency makes not only the measurement of mist suitable but also the rate of mist generation uniform. We observed that the atomization efficiency of solvents is dependent on solvent viscosity. A high viscosity causes the low atomization efficiency. The viscosities of IPA, ME and DW are $24.0 \mathrm{mPa} \mathrm{s}, 0.6 \mathrm{mPa}$ s and $1.0 \mathrm{mPa}$ s, respectively. Consequently, we have adjusted the ratio of DW, ME and IPA. The efficient device performance was obtained when DW ratio is $60 \%$ and IPA: ME is $1: 1$ to $3: 1$. The best PCE is $3.40 \%$ when IPA : ME : DW is $3: 1: 6$.

Fig. $6(\mathrm{a}$ and b) show the morphology of $5 \mathrm{~nm}$ and $30 \mathrm{~nm}$ thermal evaporated $\mathrm{MoO}_{3}$. It can be seen that, when the thickness of $\mathrm{MoO}_{3}$ is $5 \mathrm{~nm}$, the film is discontinuous, which is similar to the spray-casted one with DW precursor solution. When the thickness reaches $30 \mathrm{~nm}$, the film is quite flat and 
(a)
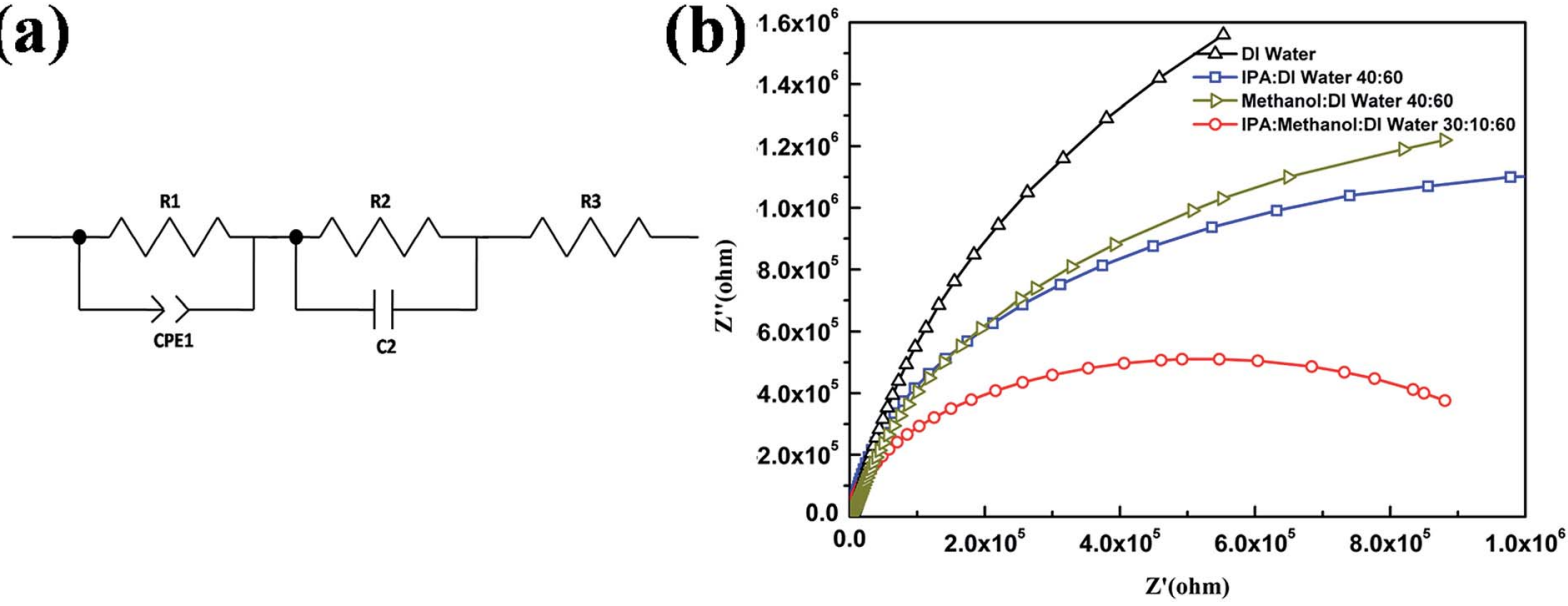

Fig. 7 (a) Equivalent circuit model of the devices. $\left(R_{1}\right.$ and $C P E_{1}, R_{2}$ and $C_{2}, R_{3}$ represent equivalent of $D / A$ interface, interface between active layer and electrodes, resistance of electrodes, respectively). (b) Cole-Cole plots of the devices with different MSS.

Table 2 Parameters employed for the fitting of the impedance spectra by use of an equivalent circuit model

\begin{tabular}{|c|c|c|c|c|c|}
\hline Device & $R_{1}(\Omega)$ & $\mathrm{CPE}_{1}-T\left(\mathrm{~F} \mathrm{~cm}^{-2}\right)$ & $\mathrm{CPE}_{1}-P$ & $R_{2}(\Omega)$ & $C_{2}(\mathrm{~F})$ \\
\hline DW & $2.45 \times 10^{3}$ & $1.07 \times 10^{-9}$ & 0.96 & $4.04 \times 10^{6}$ & $1.85 \times 10^{-9}$ \\
\hline IPA : DW $40: 60$ & $2.52 \times 10^{3}$ & $2.59 \times 10^{-9}$ & 0.95 & $2.08 \times 10^{6}$ & $1.67 \times 10^{-9}$ \\
\hline IPA : ME : DW $30: 10: 60$ & $2.57 \times 10^{3}$ & $2.68 \times 10^{-9}$ & 0.95 & $1.01 \times 10^{6}$ & $1.42 \times 10^{-9}$ \\
\hline
\end{tabular}

continuous. Based on device performance, this continuous film causes a lower performance compared with the $\mathrm{MoO}_{3}$ micro arrays via the poor conductivity.

Fig. 4(d) shows the results of external quantum efficiency (EQE) measurement for OSCs fabricated by using different solvent systems. The spectrum of the device with IPA : ME : DW solvent system shows a higher EQE than others and a maximum of $63.9 \%$ at a wavelength of $520 \mathrm{~nm}$. The relatively high EQE maybe come from an improvement of the interface contact between donor and anode. This result indicated that the solution processed $\mathrm{MoO}_{3}$ by using the MSS could lead to the improved charge transfer efficiency.

\subsection{Equivalent circuit model and impedance analysis}

To investigate the carrier dynamics, Nyquist plots were analyzed using an equivalent circuit as shown in Fig. 7. The calculated parameters are also shown in Table 2. We can see that the calculated plots are in good accordance with a simulated curve. The parallel circuit of $R_{1}$ and $\mathrm{CPE}_{1}$ represent the D/A interface, $R_{2}$ and $C_{2}$ represent the interface of active layer and electrodes, $R_{3}$ represents the resistance of electrodes. $R_{1}$ and $\mathrm{CPE}_{1}$ related to active layer for different devices are approximately identical. Real impedances $Z^{\prime}$ of OPVs decrease significantly when the MSS was contain a certain amount of IPA and ME, resulting in the high $J_{\mathrm{SC}}$ for the OSCs. ${ }^{34}$ A high $R_{2}$ of device with DW suggests that the interface between the active layer and the buffer layer is not efficient for charge transport. For devices with IPA : ME : DW in a proportion of $30: 10: 60, R_{2}$ decreased to the minimum at 1.01 $\times 10^{6} \Omega \mathrm{cm}^{2},{ }^{35}$ revealing that the interfacial resistance between the active layer and the solution processed $\mathrm{MoO}_{3}$ is minimized.

\section{Conclusions}

Solution processed $\mathrm{MoO}_{3}$ micro arrays were successfully grown on the OSC active layers by using ultrasonic spray coating method at a very low temperature of $80{ }^{\circ} \mathrm{C}$. The charge carrier transport between the active layer and the anode was improved with the solution processed $\mathrm{MoO}_{3}$ micro arrays. Thus, the $J_{\mathrm{SC}}$ and FF obviously increased, and a higher PCE was obtained. The carrier transport performance was further improved by the introduction of the MSS for $\mathrm{MoO}_{3}$ precursor. When DW ratio is $60 \%$ and IPA : ME is $1: 1$ to $3: 1$, the OSCs with solution processed $\mathrm{MoO}_{3}$ showed a highest PCE of $3.40 \%$. This technique is straight-forward, low cost, meeting the requirement of roll-toroll process and compatible with large scale and high lifetime organic photoelectric devices.

\section{Acknowledgements}

The authors gratefully acknowledge the financial support from National Natural Science Foundation of China (NSFC) (Grant Nos. 61675041, 51503022 and 61505018); the Foundation for Innovation Research Groups of the NSFC (Grant No. 61421002); Science \& Technology Department of Sichuan Province via Grant No. 2016HH0027; Technology Project from Chongqing Education Committee (Grant No. KJ1401113); Chongqing 
Science \& Technology Commission (Grant No. cstc2013jcyjys50001); Chongqing University of Arts and Science (Grant No. R2012CJ18 \& Z2013CJ02).

\section{References}

1 Q. An, F. Zhang, J. Zhang, W. Tang, Z. Deng and B. Hu, Energy Environ. Sci., 2015, 9, 281-322.

2 Q. An, F. Zhang, L. Li, J. Wang, Q. Sun, J. Zhang, W. Tang and Z. Deng, ACS Appl. Mater. Interfaces, 2015, 7, 3691-3698.

3 M. Zhang, F. Zhang, Q. An, Q. Sun, W. Wang, J. Zhang and W. Tang, Nano Energy, 2016, 22, 241-254.

4 Q. An, F. Zhang, L. Li, J. Wang, J. Zhang, L. Zhou and W. Tang, ACS Appl. Mater. Interfaces, 2014, 6, 6537-6544.

5 C. Xu, P. Cai, X. Zhang, Z. Zhang, X. Xue, J. Xiong and J. Zhang, Sol. Energy Mater. Sol. Cells, 2017, 159, 136-142.

6 Y. Liu, X. Wan, F. Wang, J. Zhou, G. Long, J. Tian, J. You, Y. Yang and Y. Chen, Adv. Energy Mater., 2011, 1, 771-775.

7 C. J. Brabec and J. R. Durrant, MRS Bull., 2008, 33, 670-675. 8 T. Wang, N. W. Scarratt, H. Yi, A. D. F. Dunbar, A. J. Pearson, D. C. Watters, T. S. Glen, A. C. Brook, J. Kingsley and A. R. Buckley, Adv. Energy Mater., 2013, 3, 505-512.

9 F. C. Krebs, M. Jørgensen, K. Norrman, O. Hagemann, J. Alstrup, T. D. Nielsen, J. Fyenbo, K. Larsen and J. Kristensen, Sol. Energy Mater. Sol. Cells, 2009, 93, 422-441. 10 C. N. Hoth, S. A. Choulis, P. Schilinsky and C. J. Brabec, Adv. Mater., 2007, 19, 3973-3978.

11 T. Aernouts, T. Aleksandrov, C. Girotto, J. Genoe and J. Poortmans, Appl. Phys. Lett., 2008, 92, 33306.

12 G. Susanna, L. Salamandra, T. M. Brown, A. D. Carlo, F. Brunetti and A. Reale, Sol. Energy Mater. Sol. Cells, 2011, 95, 1775-1778.

13 D. Vak, S. S. Kim, J. Jo, S. H. Oh, S. I. Na, J. Kim and D. Y. Kim, Appl. Phys. Lett., 2007, 91, 81102.

14 W. Ma, C. Yang, X. Gong, K. Lee and A. J. Heeger, Adv. Funct. Mater., 2005, 15, 1617-1622.

15 Z. He, C. Zhong, S. Su, M. Xu, H. Wu and Y. Cao, Nat. Photonics, 2012, 6, 593-597.

16 L. Chen, P. Wang, F. Li, S. Yu and Y. Chen, Sol. Energy Mater. Sol. Cells, 2012, 102, 66-70.

17 D. Zheng, J. Huang, Y. Zheng and J. Yu, Org. Electron., 2015, 25, 275-282.
18 G. Li, C. W. Chu, V. Shrotriya, J. Huang and Y. Yang, Appl. Phys. Lett., 2006, 88, 253503-253505.

19 J. Cheng, Q. Wang, C. Zhang, X. Yang, R. Hu, J. Huang, J. Yu and L. Li, J. Mater. Sci.: Mater. Electron., 2016, 27, 7004-7009.

20 D. Y. Kim, J. Subbiah, G. Sarasqueta, F. So, H. Ding, Irfan and Y. Gao, Appl. Phys. Lett., 2009, 95, 93304.

21 Irfan, H. Ding, Y. Gao and D. Y. Kim, Appl. Phys. Lett., 2010, 96, 73304.

22 V. Shrotriya, G. Li, Y. Yao and C. W. Chu, Appl. Phys. Lett., 2006, 88, 73508 .

23 G. Li, C. W. Chu, V. Shrotriya, J. Huang and Y. Yang, Appl. Phys. Lett., 2006, 88, 253503-253505.

24 J. R. Koo, S. J. Lee, H. W. Lee, D. H. Lee, H. J. Yang, W. Y. Kim and Y. K. Kim, Opt. Express, 2013, 21, 11086-11094.

25 K. X. Steirer, P. F. Ndione, N. E. Widjonarko, M. T. Lloyd, J. Meyer, E. L. Ratcliff, A. Kahn, N. R. Armstrong, C. J. Curtis and D. S. Ginley, Adv. Energy Mater., 2011, 1, 813-820.

26 J. Cheng, R. Hu, Q. Wang, C. Zhang, Z. Xie, Z. Long, X. Yang and L. Li, Int. J. Photoenergy, 2015, 2015, 1-8.

27 D. Parviz, M. Kazemeini, A. M. Rashidi and K. J. Jozani, J. Nanopart. Res., 2009, 12, 1509-1521.

28 S. Murase and Y. Yang, Adv. Mater., 2012, 24, 2459-2462.

29 C. Wang, I. Irfan, X. Liu and Y. Gao, J. Vac. Sci. Technol., B: Nanotechnol. Microelectron.: Mater., Process., Meas., Phenom., 2014, 32, 40801.

30 N. Wang, J. Yu, Y. Zheng, Z. Guan and Y. Jiang, J. Phys. Chem. C, 2012, 116, 5887-5891.

31 S. Murase and Y. Yang, Adv. Mater., 2012, 24, 2459-2462.

32 H. Zhou, Y. Zhang, J. Seifter, S. D. Collins, C. Luo, G. C. Bazan, T. Nguyen and A. J. Heeger, Adv. Mater., 2013, 25, 1646-1652.

33 Y. Zheng, S. Li, D. Zheng and J. Yu, Org. Electron., 2014, 15, 2647-2653.

34 E. P. Yao, C. C. Chen, J. Gao, Y. Liu, Q. Chen, M. Cai, W. C. Hsu, Z. Hong, G. Li and Y. Yang, Sol. Energy Mater. Sol. Cells, 2014, 130, 20-26.

35 Y. Zheng, T. Goh, P. Fan, W. Shi, J. Yu and A. D. Taylor, ACS Appl. Mater. Interfaces, 2016, 8, 15724-15731. 